\title{
Does participation in family medicine interest group events at Canadian medical schools influence residency decisions?
}

\author{
George Kim, Janina Mailloux, Caleb Van de Kleut \\ Faculty Reviewer: Darren Van Dam, MD, CCFP (Department of Family Medicine)
}

\section{ABSTRACT}

Undergraduate medical students established family medicine interest groups (FMIGs) across Canada to enhance their exposure to family medicine as a medical specialty. However, there has been limited research performed to evaluate if FMIGs are fulfilling their role in promoting postgraduate training in family medicine. The objective of this study was to determine whether or not participation in FMIG events influenced the residency decisions of fourth year medical students attending the Schulich School of Medicine \& Dentistry. 32 fourth year students from the class of 2015 responded to an online survey. Overall, this study determined that FMIG events provided students with a greater understanding of the opportunities in family medicine $(23 / 32)$, but did not influence residency decisions. The study was limited given the small cohort of medical students surveyed. In the future, it may be beneficial to pursue a Canada-wide research study of FMIGs to survey a larger number of students, and improve the validity and generalizability of the results.

\section{INTRODUCTION}

Currently, every medical school across Canada has a family medicine interest group (FMIG). ${ }^{1}$ The aim of these groups is to promote interest in postgraduate training in family medicine through numerous events, which include lunchtime talks, clinical skills day, and meet and greet events with family physicians. The hope behind these events is that they will ultimately promote postgraduate training in family medicine and promote family medicine as a worthwhile career. ${ }^{1,2}$ Previous research has shown that interest in a career in family medicine is influenced by having family physician mentors, ${ }^{3}$ having an interest in family medicine prior to beginning medical training, ${ }^{4}$ and taking part in electives in family medicine. ${ }^{4-6}$ However, there has been very limited research that examines the effects FMIG events have on medical students' residency decisions, and the nature of any potential influence..$^{7-9}$

The objective of this study is to determine whether or not participation in FMIG events influences the residency decisions of fourth year medical students attending the Schulich School of Medicine \& Dentistry. A pilot study was pursued in 2013 with the class of 2013. A survey was distributed to students after residency matches had been determined. The survey examined which program each student had matched to, whether or not the student attended FMIG events, and any influence these events had on their final residency decisions. The pilot study determined that FMIG events were suc- cessful in providing students with an understanding of the opportunities available in family medicine. However, residency decisions were not influenced by FMIG events. The pilot study did not have ethics approval, and involved a small cohort of medical students $(n=26)$.

This current study involved the class of 2015, and received ethics approval from Western University. Results of this study were to be used to determine the efficacy of current programs implemented by FMIG, and to guide the development of future programs. The ultimate hope is that this study can be implemented as a Canada-wide research study investigating the impact of FMIG events on residency decisions in all Canadian medical schools.

\section{PROGRAM DESCRIPTION}

The FMIG at Western University was established in April of $2001 .^{2}$ The FMIG committee is composed of a faculty representative, 4 co-chairs ( 3 from the London campus, 1 from the Windsor campus), and 4 co-executives ( 3 from the London campus, and 1 from the Windsor campus).

The FMIG committee meets monthly to discuss and plan events to promote postgraduate training in family medicine. The events held in 2015 included the following:

\section{(1) Monthly lunchtime talks}

These events involved family physicians or residents speaking about why they chose family medicine, as well as practice settings and special interests in practice (ie dermatology, emergency medicine, obstetrics).

\section{(2) Clinical skills day}

This is the largest FMIG event at Western, attended by over 100 students. The day involves various workshops led by physicians and residents that teaches skills such as suturing, punch biopsies, and intravenous line insertion.

(3) Mix and mingle

This event occurs once a year, and allows undergraduate medical students the opportunity to speak with residents and physicians one-on-one.

\section{(4) Family Health Network field trip}

Invitations for this event were sent online to student FMIG members at Western, and spots were filled on a first-come, firstserved basis. Students were able to visit a Family Health Network in London, which included a tour and presentation by the staff physician.

(5) Mentorship program

This new program was established at Western University in 2014. Student FMIG members were matched with current family 
medicine residents at Western University. Students were connected with their mentors individually, allowing them an opportunity to ask questions about family medicine or arrange clinical observerships.

\section{METHODOLOGY}

The study was a retrospective cohort study involving class of 2015. Students were emailed an online survey using the program SurveyMonkey ${ }^{\circledR}$ after their residency matches had been determined, and participation was voluntary. 32 students completed the survey. The survey involved 9 questions relating to the following themes:

\section{(1) Participant demographics}

Q1: Were you a member of the FMIG?

Q2: Which specialty did you match to?

Q3: Which specialty were you most interested in at the beginning of medical school?

Q4: Were you involved in the planning of FMIG events (ie, as an executive in 1st or 2nd year)?

(2) Specific FMIG events and their effect on residency decisions Q5: Which of the following FMIG events did you attend? Q6: This question involved parts (a) to (d) using 5-point Likertstyle questions evaluating the effect the FMIG program and events had on residency decisions.

(3) Overall effect of FMIG events on residency decisions

Q7: If you attended any of the above FMIG events, which had the most influence on your residency decision(s)?

(4) Specific recommendations for improvements of FMIG events.

Q8: How do you feel FMIG events could be improved?

Q9: Do you feel there were enough FMIG events offered to students?

The data were analyzed as nominal data. Survey responses to Likert-type questions were not converted to ordinal data.

\section{RESULTS}

32 fourth year students responded to our survey. Not all survey respondents responded to every question; some chose to skip certain questions. 18 respondents were members of the FMIG. 18 respondents matched to family medicine, and 14 matched to other specialties. Interest in specialties was widespread among respondents at the start of medical school, with only 5 indicating interest in family medicine (Figure 1). For "other" options, responses included 3 students indicating emergency medicine as their area of interest, and an additional 3 were interested in pediatrics.

31 survey respondents were not involved in FMIG event planning, while 1 was. As expected, the clinical skills day was the best attended FMIG event with 25 respondents who had attended. Monthly talks attracted 12 respondents (Figure 2).

Among survey respondents who attended FMIG events (26), $16 / 26$ strongly agreed that FMIG events educated students about opportunities available in family medicine (Figure 3). 9/26 respon-

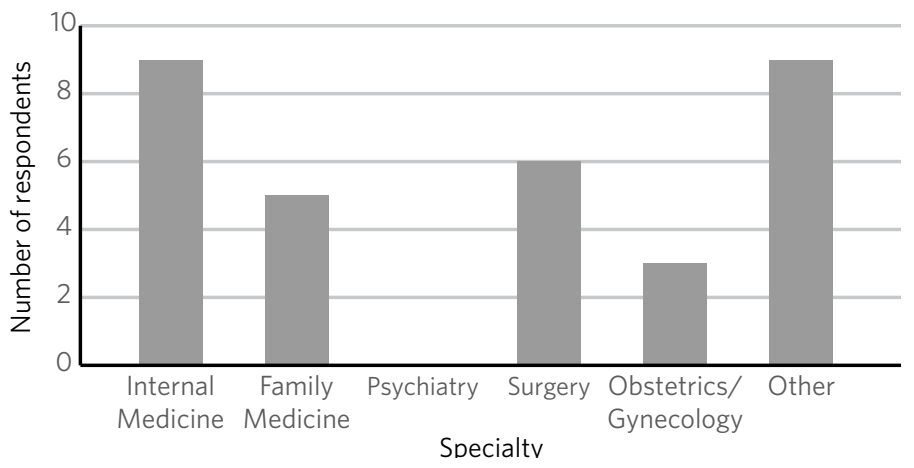

Figure 1. Specialty of interest at the start of medical school.

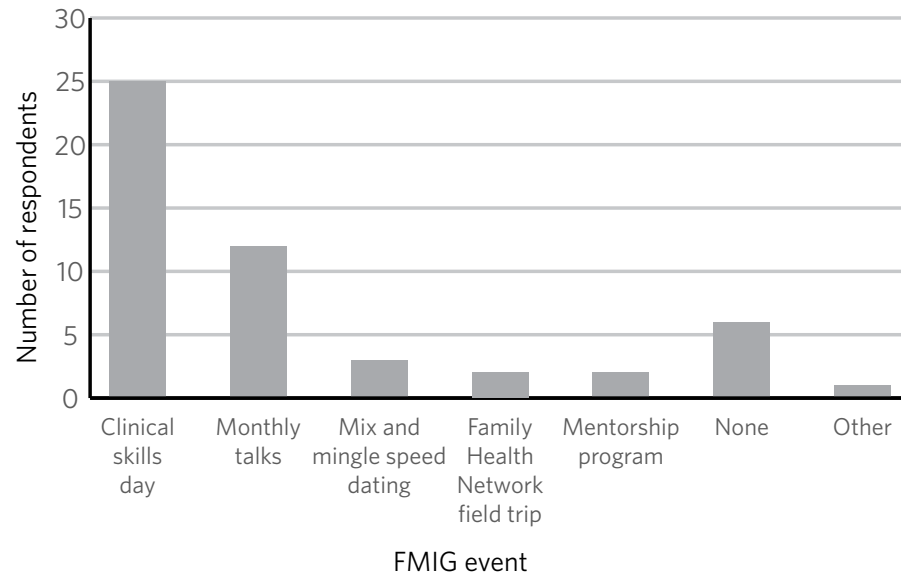

Figure 2. FMIG events attended.

dents agreed strongly (2/9) or weakly (7/9) that FMIG events influenced residency decisions while $7 / 26$ disagreed strongly (3/7) or weakly (4/7) with that statement. FMIG events did help respondents consider family medicine as a career with 15/26 agreeing either strongly $(5 / 15)$ or weakly (10/15). FMIG events did not serve to help respondents rule out family medicine as a specialty, with $17 / 26$ strongly disagreeing with this statement, and an additional

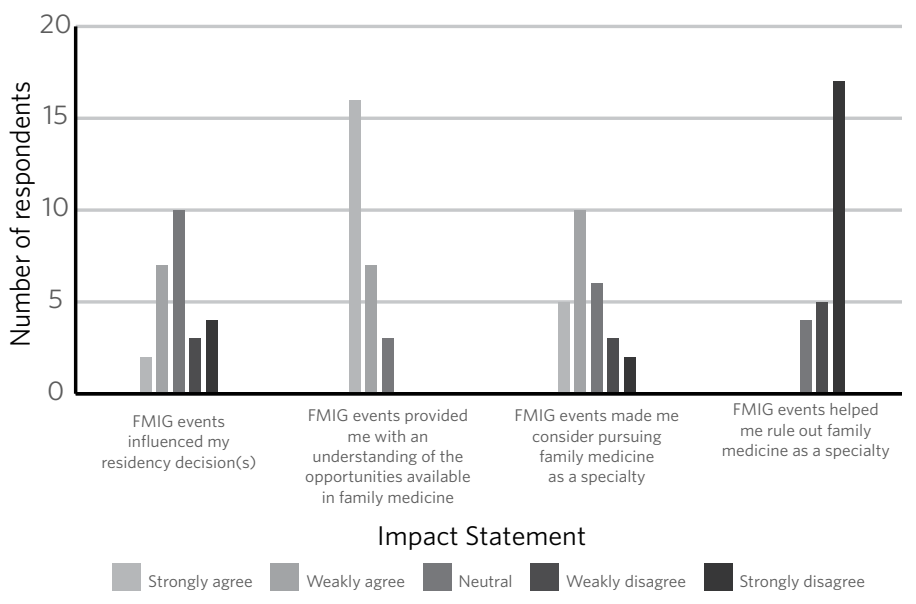

Figure 3. Responses to the statements about the impact of FMIG events. 
5/26 weakly disagreeing.

Of those respondents who attended FMIG events (26/32), 6 indicated that the clinical skills day had the most impact on residency decisions. 2 responded that the monthly talks were most influential, and an additional 2 indicated that mix and mingle event impacted residency decisions the most. 16 responded indicating that no FMIG events impacted residency decisions. 9/32 students abstained from indicating how they thought FMIG programming could be improved. Of the $23 / 32$ who responded about improvement ideas to FMIG events, 17 wanted more hands-on workshops and 12 wanted more time to speak with residents (Figure 4).

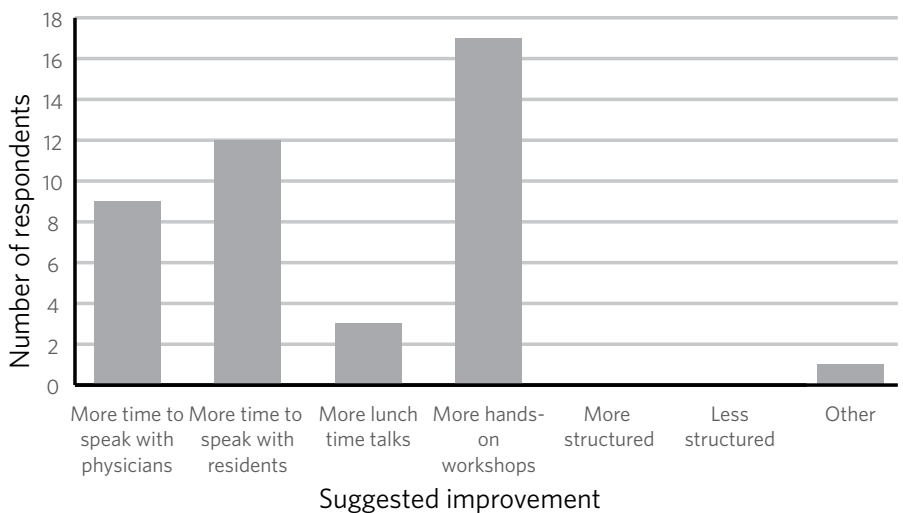

Figure 4. Suggested future improvements to FMIG events.

30 respondents indicated that they felt there was a sufficient number of FMIG events. The remaining respondents did not answer this question.

\section{CONCLUSION}

Undergraduate medical students have established FMIGs across Canada to enhance student exposure to family medicine as a medical specialty. However, there has been limited research performed to evaluate whether or not FMIGs are fulfilling their role in promoting postgraduate training in family medicine. Our study of the class of 2015 evaluated whether of not participation in FMIG events influenced residency decisions $(n=32)$. Overall, the results demonstrated that FMIG events are successful in providing students with an understanding of the opportunities available in family medicine, with $72 \%(23 / 32)$ of respondents agreeing to this statement. However, residency decisions were not influenced by FMIG events.

Our study was limited given the small cohort of medical students surveyed. Therefore, statistical analysis of the data could not be completed. A potential barrier that prevented our study from being adequately powered is that final-year medical students are busy with the culmination of medical school. Participation in a survey during this stressful time in their careers may be difficult to obtain.

To survey a greater number of students, we hope to pursue a Canada-wide research study in the future. Increased survey participation would improve the validity and generalizability of the results. These results could then be used to improve FMIG events at all Canadian medical schools. We believe that if FMIGs do an excellent job of education, more medical students will choose family medicine. If we are successful in this endeavor, we will begin to help address the current shortage of primary care physicians.

\section{REFERENCES}

1. The College of Family Physicians of Canada: Family Medicine Interest Groups (FMIG) website [Internet]. Mississauga, Ont: College of Family Physicians of Canada; 2004. [Cited 2015 Oct]. Available from http:// www.cfpc.ca/FMIGs.aspx

2. Family Medicine Interest Group website [Internet]. London, Ont: The Schulich School of Medicine \& Dentistry; 2015. [Cited 2015 Oct]. Available from http://www.schulich.uwo.ca/familymedicine/undergraduate/family_medicine_interest_group.html

3. Jordan J, Brown JB, Russell G. Choosing family medicine; what influences medical students? Can Fam Physician. 2003;49:1131-7.

4. Senf JH, Campos-Outcalt D, Kutob R. Factors related to choice of family medicine: a reassessment and literature review. J Am Board Fam Pract. 2003;16:502-14.

5. Xu G, Hojat M, Brigham TP, et al. Factors associated with changing levels of interest in primary care during medical school. Acad Med. 1999;74(9):1011-5.

6. Musham C, Chessman A. Changes in medical students' perceptions of family practice resulting from a required clerkship. Fam Med. 1994 Sep;26(8):500-503.

7. McKee N., McKague M, Ramsden V, et al. Cultivating interest in family medicine: Family medicine interest group reaches undergraduate medical students. Canadian Family Physician. 2007, 53(4): 661-5.

8. Rosenthal TC, Feeley T, Green C, et al. New research: family medicine interest groups impact student interest. Fam Med. 2004;36:463.

9. Baraka SM, Ebell MH. Family medicine interest groups at US medical schools. Fam Med. 1995;27:437-9. 